\title{
Explore the Existing Problems and Solutions on the Stadium Building Management of Independent Colleges
}

\author{
Jinglun Yang ${ }^{1, a}$, Lan Chen ${ }^{2, b}$ \\ ${ }^{1}$ Sports education center,Zhuhai College of Jilin University,Zhuhai 519041,China \\ ${ }^{2}$ Laboratory and assets management office,Zhuhai College of Jilin University, Zhuhai 519041,China \\ ayangjinglun1983@163.com, ${ }^{b} c h e n l a n 19841009 @ 163 . c o m$
}

Keywords: independent colleges, stadium building, management.

\begin{abstract}
The independent colleges are considered as the important components of higher education institutions in China. However, the stadium buildings are not well managed at the moment. There are three major existing problems: unreasonable structures of administrative staff with lower comprehensive quality; insufficient management system and outdated information construction; insufficient investments and delay of discarding and replacing the sports equipments. For the independent colleges, the three urgent tasks are illustrated as follows: strengthen the personnel management and training; improve the management system and information construction; transform the out-dated ideas and attach great importance to the stadium building construction and equipment maintenance. In this way, it is possible to do well with the statium building management and levarage the maximum impact in the management efficiency of stadium buildings.
\end{abstract}

\section{Introduction}

The independent colleges are the higher educational institutions of conducting the undergraduate education. Based on the new education mechanism and pattern ${ }^{[1]}$, these secondary schools are collaboratively organized by the general undergraduate colleges and social forces. Till now, there are more than 300 independent colleges throughout the country. These collges are considered as the dominant forces in developing the higher education in China. At the same time, the statium buildings are the major sites for the teachers and students to take the physical education, athletic training, physical exercises, extra-curricular activities, sports competitions and son on. However, the majority of these statium buildings are not well managed. For instance, lack of the high quality management team with the rational structures; lack of the stanardized management system and out-dated information construction modes; insufficient investment funds and delay of discarding and replacing the sports equipments, etc. These undesirable situations have brought about many problems so that the teachers and students can not fully enjoy the pleasure of doing exercises in the stadium. For this reason, the independent colleges shall reflect on the current situations, propose the corresponding solutions, exert the greater influence in the management efficiency of statium building, create the favorable environment of taking exercises, improve the enthusiasm of the teachers and students to join in the physical activities. The highly efficient, scientific and standarized management of the school stadium are of great importance for the lifelong sports undertakings in China.

\section{Explore the existing problems on the stadium building management of our independent colleges}

\subsection{Unreasonable structures of administrative staff with lower comprehensive quality.}

The integrated management level of the school stadium is subject to the education background, specialty and professional title of the stadium administrators in some way. Since the independent colleges go through the fast start-up, the employed administrators have no management experiences and professional management specialty, especially for the young undergraduates or junior college students. In this way, the stadium administrators generally have the disadvantages such as 
unreasonable structure, lack of management experience and lower comprehensive quality. The unreasonable structure is majorly presented as the undergraduate degree or postgraduate degree with primary and medium-grade professional title. According to our investigations, it is found that the administrators below the undergradute degree are generally the disposable teachers; the administrators with undergraduate degree or above are treated as the regular teachers. The kind of management team will produce a certain impact in the efficient stadium mangement of independent colleges. The insufficient managerial experience is majorly reflected in the professional background of the stadium administrators. In this case, the personnel ratios of sports specialty are highest, followed by other specialties. There are very few of the personnel with management specialty or sports management specialty. The administrators' professional background does not match with the stadium building management works. As a consequence, the administartors without the professional knowledge and experiences will certainly prevent the improvements of the stadium building management level. The lower comprehensive quality is majorly reflected in the following aspects: The stadium administrators are generally content with the status quo, lack of working enthusiasm and sense of responsibility. All of these factors have further interfered with the stadium building management at the long term.

\subsection{Insufficient management system and outdated information construction.}

The management system is fundamental to the daily management of the school stadium and the smooth development of sports activities among the teachers and students; the imperfect management system and unsatisfactory execution force will produce a direct influence in the efficiency of stadium building management ${ }^{[2]}$. In order to improve the daily management of the school stadium, the independent colleges shall set up a set of standardized, detailed and efficient policy system in the stadium building management. According to the findings, it is found that the independent colleges are unable to completely implement the daily management system. At this point, the standardization, operability and enforcement of the management system shall be further improved. With regard to the standardization of management system, it is found that many regulations and rules are not practicable, that is to say that the regulations and rules are not correlated with the specific purposes. With regard to the operability of management system, the related enforcement regulations and rules are not precisely formulated to highlight the human-based management concept. The detailed rules and regulations are just listed while its operability and significance is easily overlooked. On account of the enforcement of management system, the supervisors rarely check whether the related personnel have duly carried out their jobs in the daily life. Most of the supervisors just make the face-to-face inquiry on the working progress. They are impossible to make the regular inspection and occasional spot checks on the execution process of the system.

In addition, the majority of the domestic independent colleges adopt the conventional labor management mode. In this case, it has the disadvantages of large workloads, low efficiency of data query, poor management effect, etc. The information between the stadiums and stadiums is not searchable while the administrators are lack of information exchanges with each other. In the end, the insufficient system construction and out-dated information construction has greatly hindered the efficient management of the stadium buildings in the independent colleges.

2.3 Insufficient investments and delay of discarding and replacing the sports equipments. With the deepening reform of the educational system, the physical education plays a bigger role in the teaching of the physical education knowledge and sports skills, enhancement of the student's physique and development of the student's wills and character ${ }^{[3]}$. Influenced by the traditional teaching concepts, the physical education has not been seriously valued, especially for the independent colleges. Under such circumstances, the independent colleges have not enough investments in the infrastructure construction, equipment installation and later-stage maintenance, which it has greatly restricted the development of the school stadium.

Since the indepdent colleges wish to save the funds in the earlier stage, the construction of the school stadium and installation of sports equipments often get into a mistake. The school stadium is not designed in the reasonable way. In this case, the teachers and students are unable to do the 
physical exercises in the high-end, standardized and harmonious envinronment. In addition, the independent colleges will rarely purchase the multi-function and modern new sports equipments. In the later stage, the sports equipments have to be frequently transformed and maintained. The replacement cycle of sports equipments are shortened and the failure rate of the sports equipments is increased. Although the funds are decreased in the earlier stage, the funds are incresased in the later stage. Thus it will bring an adverse effect in the physical education. In the later stage, the reports of discarding and replacing the sports equipment and investment funds are not properly delivered. As a result, the maintenance time of sports field and sports equipments is often extended. Without the enough maintenance costs and long-term planning, the maintenance of sports field and sports equipments is delayed in the later stage and the old equipments are not properly replaced. What's more, the chance of potential risks is increased. Consequently, the teachers and students are not possible to do the physical exercises in the safe, elegant and perfect environment.

\section{Find out the solutions of improving the stadium building management Page}

\subsection{Enhance the personnel management and training.}

The outstanding stadium building management efficiency has a close correlation with the arrangement of the high-quality administrators. In order to improve the management level of the school stadium, the independent colleges shall start from the personnel management and training to improve the comprehensive quality of the stadium adiminstrators and achieve the scientific management ${ }^{[4]}$. To begin with, the college leardership has to improve the threshold of applying for the stadium administrators so as to bring in more experienced young people and middle-aged talents of taking the lead, optimize the age structure of the administrators and accelerate the dynamic development of the administrators. Next, the independent college shall focus on the internal training and strengthen the professional training of the stadium administrators. For instance, the independent colleges shall try to organize the stadium administrators to make the on-the-spot investigation and communication with the preferable universities and learn from their successful managerial experiences. In other way, it is possible to invite the experts to deliver the related lectures or open the online courses. The new management methods and concepts will be introduced so that the stadium administrators are possible to understand the latest management methods, learn from the front-end managerial experiences, improve the individual comprehensive quality and the stadium management efficiency.Finally, what is worthy of noting is that the stadium administrators has to accept the professional ethnics education, improve the strong sense of responsibility and do well with the stadium building management.

\subsection{Improve the management system and information construction and achieve the management goals.}

The primary mission for the school stadium is to maintain the normal physical teaching activities. In order to improve the service quality and use efficiency of the stadium, it is fundamental to establish the sophisticated rules and regulations. During the establishment of the management system, the independent college shall completely prevent the "borrowlism". In particular, the affiliated colleges often copy the existing management system that is drawn up by the alma mater. However, every college has its special characteristics. Therefore, the independent colleges shall fully understand the general information of their personnels. The related departments (e.g dean's office, logistics department, equipment division, security guard department, physical education center) are also responsible to set up the corresponding system with regard to the physical education, construction planning, security maintenance, use of equipments, out-put and in-put of ware house for consumable items and daily management. Each department shall actively participate in the discussions to determine the comprehensive schemes and establish the special, systematic and comprehensive daily management regulations and rules. During the implementation of the rules and regulations, the independent college shall make the reform on the existing management modes and positively explore the method of "foreign contract and school supervision". On the one side, the independent colleges shall improve the administrator's management efficiency; on the other side, the colleges shall promote the continuous improvement of management concepts and adjustment of management 
methods. With regard to the information construction, the majority of independent colleges still adhere to the concept of "labor management". Obviously, the labor management does not conform to the development of the society informatization. The independent colleges have to keep pace with the times and positively learn from the advanced management methods of the large-scale stadium. For instance, it is possible to set up the information-based system on the entrance guard, online ordering of the stadium buildings, equipment maintenance, out-put and in-put of warehouse for consumable items. The information system is reachable to improve the management efficiency and better serve the teachers and students.

\subsection{Transform the out-dated ideas and attach great importance to the stadium building construction and equipment maintenance.}

The physical education has its special characteristics to improve the adolescent's physical and psychological health, physique and humanistic cultivation. The college leardership shall freshen up the old ideas, further understand the necessity and importance of the physical education in the talent cultivation, reasonably allocate the college's educational expenditures, establish the sound system in the funds management and increase the input ratios. At the long term, the colleges shall make the scientific and reasonable planning and design on the stadium buildings, offer the elegant and perfect site, lay emphasis on the multiple functions of the sports equipments, improve the performance of physical exercise, positively develop towards the direction of public physical training and entertainment. Under such circumstances, the school stadium will become the integrated place of sports competition, fitness, entertainment and leisure.

With regard to the physical education funds, the independent colleges shall take the full advantage of the existing sports resources like sports field and sports equipments. Once the paid-use system is established in the society, it is able to enhance the incomes and extend the capital channels. In this case, some of the stadium buildings are able to open to the society in the winter and summer vacation and holidays. The financial resources will be properly increased. Secondly, the independent colleges shall increase the captial investment ratios, make the scientific budgets on the pysical education funds, improve the supervision system and enhance the transparency and efficiency of using the funds. Thirdly, in order to gaurantee the personnel safety, it is necessary to take a regular maintenance to properly replace the shabby sports apparatus. In this way, the college leardship shall attach importance to the investment of the subsequent funds. The service life of the sports equipments are greatly determined by the administrators' daily management and maintenance. Therefore, the stadium administrators have to focus on the daily maintance of the sports equipments and do well with dust prevention, sun block, damp proof and rust protection. These equipments have to be kept in the good state. Once the management and maintenace of sports equipments is concerned, the investments on the physical education will be relatively decreased.

\section{Summary}

The school stadium is the most fundamental material condition of doing the physical exercises, competitive sports activities, physical education and extensive fitness programs. In addition, it is a kind of the methods for the colleges to give the humanistic care. The sports culture taste is also reflected in this aspect. From this reason, the college learship shall attach great importance to the construction of school stadium, organizing the high quality management team with reasonable structure, professions and experiences. It is also necessary to improve the management system of the stadium, explore the way of information construction, promote the efficient operation of the school stadium and further develop the spirits of doing the lifelong sports exercises.

\section{References}

[1] Tang Ying, Analyze the existing problems and solutions of the college stadium management in Changchun, Jilin University,2015. 
[2] Zheng Luming, Study the current situation and countermeasures of sports facilities in the middle schools of Changchun City, Jilin Sport University,2015.

[3] Yang Jinglun, Study the current situation and countermeasures on the construction of teaching staff in the independent college, Sport,2016,05:101+100.

[4] Feng Lei,Zhou Yang, Probe into the management of the stadium building management in the college, Science \& Technology of Stationery \& Sporting Goods, 2016,10:26-27. 